\title{
Participação em Lucros e o Programa de Integração Social.
}

\author{
Nair Lemos Gonçalves \\ Professora Titular de Direito do Trabalho da \\ Faculdade de Direito da Universidade de São Paulo.
}

\begin{abstract}
SUMÁRIo: A grande solidariedade no campo do trabalho. Diversidade na organização do trabalho. $O$ PIS como participação nos lucros (1. ${ }^{\text {a }}$ fase). $O$ PIS como participação nos lucros e na renda nacional (2. ${ }^{a}$ fase). Proscrição da despedida imotivada.
\end{abstract}

Introdução - Oferecemos este trabalho, na qualidade de relatora nacional, ao Congresso Latino-Americano de Direito do Trabalho e Previdência Social, realizado em S. Paulo, no mês de setembro de 1976.

Foi nosso objetivo apresentar os argumentos em que baseamos nossa convicção de que o Programa de Integração Social - PIs, em sua primeira fase (até a fusão com o Programa de Formação do Patrimônio do Servidor Público - PASEP, determinada pela Lei Complementar n. ${ }^{\circ} 26 / 75$ ) pode ser considerado programa de participação dos trabalhadores nos lucros das empresas. Na segunda fase, iniciada em 01 de julho de 1976, vemos a ampliação do programa, através de mecanismo ou técnica econômica, social e jurídica mais abrangente que, sem deixar de ser, para os trabalhadores, um programa ainda, em parte, de participação nos lucros, tem agora como objetivo principal a redistribuição de parte da renda nacional, por meio de concessão de vantagens principalmente à grande maioria dos assalariados (empregados ou servidores públicos) menos favorecida economicamente (pessoas que percebem salário de valor até cinco vezes o salário mínimo regional). Do ponto de vista macroeconômico, entendemos que, em ambas as fases, o PIS permanece com a mesma finalidade principal de, a um tempo, impedir a descapitalização das empresas e reunir recursos destinados a incentivar a realimentar economicamente todos os ramos de atividade, tenham ou não finalidade diretamente lucrativa. 
Reconhecemos, através do PIS, a participação do trabalhador no desenvolvimento das empresas, não sendo suficiente para promover a integração do empregado na vida da empresa como exige o dispositivo constitucional (art. 165, V, da Const. Fed. na redação dada pela Emenda Constitucional n. ${ }^{\circ}$ 1/1969).

Os mais importantes programas e mecanismos econômicos criados no Brasil em benefício do trabalhador, regra geral, têm sua eficácia condicionada principalmente à existência de relação de emprego. Em outras palavras, o assalariado é protegido se, enquanto e quando trabalha, decorrendo a proteção, em outras hipóteses, do fato de haver trabalhado. Sem esquecer os diversos regimes de previdência social vigentes, referímo-nos principalmente ao Fundo de Garantia do Tempo de Serviço, ao Programa de Integração Social e ao Sistema Nacional de Habitação.

Por esse motivo, no que tange aos assalariados, a proscrição da atual autorização legal da despedida imotivada constitui, a nosso ver, a primeira e principal medida necessária e indispensável à integração do empregado na vida da empresa e também para assegurar a eficiente execução dos importantes programas econômicos referidos. Isto não quer dizer a volta ao antigo regime da estabilidade e sim o reconhecimento da exigência, para toda despedida, da existência de motivo socialmente aceitável, como acontece em outros países.

\section{A Grande Solidariedade no Campo do Trabalho.}

Contamos no Brasil com o mais demócratico dos princípios constitucionais que proibe distinção entre "trabalho manual, técnico ou intelectual ou entre os profissionais respectivos" (art. 165 XVII, Const. Fed. — redação da E. C. n. ${ }^{\circ}$ 1/1969). A distinção aqui proibida prevalece ainda nos países em que a legislação estabelece regimes diferentes para empregados e operários. Trata-se de princípio constitucional tradicional em nossa Pátria, porque esteve presente nas Constituições de 1934 (art. 121, § $2^{\circ}$ ), de 1946 (art. $157 \S 1 .^{\circ}$ ), de 1967, redação primitiva (art. 158, XVIII), tendo a Carta Constitucional de 1937 garantido igual proteção ao trabalho intelectual, técnico ou manual (art. 136).

Entende-se que assim ocorra, pois há inegável inter-relação e interdependência entre todas as atividades humanas, até as que se realizam no recesso dos lares. (Costumamos salientar aos nossos alunos que o cientista nuclear, para citar um dos 
mais elevados trabalhos intelectuais e técnicos, pode prejudicar seu desempenho profissional quando não encontra no lar a necessária tranqüilidade, perturbada pela falta de simples empregada doméstica). Indispensável, portanto, no campo do trabalho, a grande solidariedade, sobre a qual repousa o progresso de todas as Nações. A importância da solidariedade é tão grande que, entre os princípios constitucionais que regulam a ordem econômica e social, encontra-se a "harmonia e solidariedade entre as categorias sociais de produção" (art. 160, IV, C.F.E.C. n. $1 / 69$ ), disposição que, confrontada com a correspondente da redação original "harmonia e solidariedade entre os fatores da produção (art. 157, IV), significa ampliação do princípio para abranger a solidariedade entre capital e trabalho (fatores da produção) e também solidariedade entre as diversas categorias econômicas ou entre as categorias profissionais.

\section{Diversidade da Organização do Trabalho.}

Inegável também que a organização do trabalho não é, nem pode ser uniforme, exigindo, por isso, múltiplos instrumentos sociais, econômicos e jurídicos para garantir : ao trabalhador as medidas de tutela ou proteção a que faz jus e também o pleno exercício dos direitos e deveres próprios não só da atividade profissional que desenvolve, mas também de sua condição de ser humano; às empresas, condições de segurança e estabilidade indispensáveis ao desenvolvimento econômico e ao Estado meios para bem cumprir as elevadas funções que a sociedade moderna lhe impõe quando, a cada dia, aumenta sua atividade social, econômica e jurídica.

Vemos então, para ficar apenas na parte referente ao trabalhador: atribuição direta às empresas da responsabilidade quanto a medidas de tutela do trabalho subordinado; intermediação de terceiros quando motivos econômicos ou sociais não aconselham ou mesmo impedem a responsabilidade direta da empresa ; e, finalmente, a auto-proteção coercitivamente impos$t a$, quando se trata de trabalhadores autônomos. Assim, para evitar dificuldades de emprego da mulher e dos trabalhadores com pesados encargos familiares, estabeleceu a lei a intermediação do Instituto Nacional de Previdência Social, incumbido de pagar o salário-maternidade e o salário-família; para atender à impossibilidade do estabelecimento de relação de emprego, nas hipóteses de prestação de trabalho subordinado eventual, criou a lei a intermediação do sindicato, como acontece na zona portuária com os trabalhadores avulsos; para afastar o traba- 
lhador do perigo de frustração de seus direitos pecuniários pela deficiência econômica das empresas, determinou a lei a retirada antecipada, do patrimônio das empresas, de recursos destinados a satisfazer principalmente às indenizações devidas, instituindo o Fundo de Garantia do Tempo de Serviço; e, o que mais nos interessa neste momento, instituiu-se o Programa de Integração Social (PIS) para afastar o grande obstáculo à participação nos lucros, considerado por BEZERRA DE MENEZES * "argüição engenhosa", aue designa como igualdade impossivel, e reconhecido posteriormente por CESARINO JÚNIOR **, isto é, a diversa rentabilidade das empresas e a variada proporção entre o número de empregados da empresa e a respectiva rentabilidade.

Projetadas no ordenamento jurídico, cada uma dessas formas de atender a necessidades da organização não uniforme do trabalho vai sendo estudada pelas diversas disciplinas jurídicas, provocando sérias controvérsias, criadas pela diversidade de posições assumidas pelos estudiosos, conforme a área do Direito a que pertencem. Basta lembrar que alguns vêem nos recursos canalizados para o PIS verdadeiro imposto, outros contribuição parafiscal, outros complementações salariais, outros, como nós, talvez não baseados nos mesmos argumentos, participacão nos lucros compatível com a Constituição Federal vigente.

Concebida a participação nos lucros tradicionalmente, no Brasil e fora dele, como instituto jurídico através do qual o empregado participa dos lucros da empresa para a qual trabalha e que, por isso mesmo, constitui meio de integração do empregado na vida da empresa, difícil, à primeira vista, reconhecer como participação nos lucros mecanismo econômico, social e jurídico que garante ao empregado parte dos lucros das empresas consideradas como um todo, porque a lei estabeleceu o "pool" de recursos. Mais fácil será identificar na hipótese "participação na renda nacional" $\left(7 .^{\mathrm{a}}\right)$, "instrumento de redistribuição da renda global" (5), "participação dos trabalhadores no desenvolvimento nacional" (como reconhecido nos debates parlamenta-

* "Não convence a argüição engenhosa, que estou em designar da igualdade impossivel, tão freqüentemente articulada contra a participação direta, ou seja a de que ela criará situações injustas, em virtude de empregados de determinadas empresas estarem sujeitos a perceber quotas inferiores às que perceberão empregados de outras mais prósperas."

** "A única objeção realmente ponderável ao sistema que propomos é, a nosso ver, a da diferente rentabilidade das empresas e a sua discrepância com o número de seus servidores. Empresas pouco rendosas têm muitos empregados e vice-versa." " 
res - DCN de 04-09-70, p. 0611), participação dos empregados "nos resultados do progresso econômico" (3).

Deixaremos para os debates, auxiliados pelas valiosas contribuições dos participantes deste Congresso, a questão da natureza jurídica, de um lado, dos recursos com que se forma $o$ Fundo de Participação do PIS e, de outro, a das quotas desse Fundo, a que fazem jus os empregados.

\section{Programa de Integração Social - PIS (1. ${ }^{a}$ fase $)$.}

Reconhecemos no Fundo de Participação formado na $1 .^{a}$ fase do PIS verdadeira solidariedade patronal, imposta coercitivamente pela lei, com fundamento na inegável e já mencionada inter-relação e interdependência de todas as atividades humanas.

Esclarece o Governo na exposição de motivos que acompanhou o projeto transformado na Lei Complementar 7/70: "O Fundo de Participação resulta de deduções no imposto de renda e de recursos próprios das empresas, de tal sorte e em tal proporção que nenhum sacrifício ponderável se impõe a essas mesmas empresas". Mais adiante, depois de esclarecer a forma pela qual os empregados receberão as quotas respectivas, informa que tal participação se fará em "um fundo global, cuja fonte única não é a empresa, pois também o Governo abre mão em prol do Programa de Integração Social, de uma parcela de sua receita." (Grifo não é da citação).

Cabe neste ponto perguntar: Haverá realmente diferença entre admitir o Governo, a título de incentivo, o desconto para efeito do cálculo do imposto de renda das importâncias dos lucros distribuídas pelas empresas a seus empregados e a dedução feita, pelo mesmo Governo, do imposto de renda arrecadado, a fim de canalizar a parte deduzida para o Fundo de Participação? Se a Constituição Federal vigente assegura aos trabalhadores, como direito, o recebimento de parte dos lucros, poder-se-â afirmar que a dedução determinada pela Lei Complementar $7 / 70$ corresponda a importância retirada da receita do Governo?

A primeira hipótese já foi lembrada entre nós para solução do problema da participação nos lucros. RUY DE AZEVEDo SoDRÉ ${ }^{10}$ a aplaudiu quando se referiu ao projeto de lei $n .{ }^{\circ} 14$, de 1959, do deputado PAULO DE TARSo, que considerava "como dedução para fins de legislação fiscal de renda, a importância 
total distribuída, direta ou indiretamente, aos trabalhadores, a título de participação nos lucros da empresa."

Nem se poderá dizer que a compulsoriedade determinada pela Lei Complementar 7/70 desfigura a participação nos lucros, porque seu caráter obrigatório apareceu na Constituição de 1946. Por outro lado, a "flexibilidade" contida na norma constitucional vigente, reconhecida por MANOEL GONÇALVES FERREIRA FILHo ${ }^{6}$, não exige participação direta nos lucros, podendo-se concluir ser dispensável a relação empresa-empregado, considerados do ponto de vista individual. O sentido social pode levar, como levou, à adoção da fórmula que atende a todos os empregados como um todo e esse objetivo o PIs alcançou quando formada a grande solidariedade patronal.

ALMANSA PASTOR ${ }^{1}$ esclarece poder realizar-se a classificação da solidariedade através de múltiplos critérios. Assim, por exemplo, diz ele, quanto ao tipo de interação, pode haver solidariedade direta, isto é, com determinação concreta das partes interativas, e solidariedade indireta, quando a interação se realiza com desconhecimento mútuo e indeterminação das partes. Por outro lado, quanto à motivação ou fonte, a solidariedade pode ser ética ou moral, imposta pela consciência, ou por preceitos morais, ou normativa ou jurídica, se estabelecida vinculadoramente pelo Direito.

Não será o PIS, na sua primeira fase, exemplo de solidariedade patronal indireta e normativa?

Vejamos a segunda fonte de recursos, a saber a parte paga proporcionalmente ao faturamento. Não se pode, regra geral, afastar a hipótese de constituir até essa porcentagem importância correspondente a lucro. Sabemos que o preço de venda inclui, em nossa organização econômica, o preço do custo $+o$ lucro. Assim como é possível desconto de imposto de renda na fonte, vemos nos recursos do PIS provenientes da porcentagem sobre o faturamento uma espécie de participação nos lucros na fonte. MESsias Donato ${ }^{5}$, com razão, vê a possibilidade de a contribuição sobre o faturamento incidir sobre perdas. Mas, com o progresso econômico do Brasil, será esta a regra geral? Se a regra geral fosse o prejuízo, estaríamos caminhando seguramente para o caos econômico, o que não nos parece verdadeiro.

Compreende-se que a lei, considerando ainda a interdependência de todas as atividades, especialmente de todas as espécies de trabalho assalariado, para o desenvolvimento econômico na- 
cional, tenha encontrado formas excepcionais de recolhimento de recursos por parte de instituições financeiras, sociedades seguradoras e outras empresas que não realizam operações de venda de mercadorias, bem como as isentas do pagamento do imposto de renda e as que não tenham fim lucrativo.

Há ligação direta, na primeira fase do PIs, entre o Fundo de Participação resultante da grande solidariedade patronal e a conta de cada empregado considerado individualmente, calculando-se as respectivas quotas proporcionalmente aos salários e ao tempo de serviço.

A exposição de motivos governamental deixou claro o interesse, a um tempo, individual e social, que inspirou a criação do mecanismo econômico quando, após referir-se ao "grande projeto nacional de desenvolvimento", continua: "Queria, assim tornar bem claro que o fortalecimento da estrutura das empresas, pela preservação de sua rentabilidade suscita a união das energias do trabalhador e do talento empresarial, constituindo fórmula prática para permanente e indispensável harmonia entre capital e trabalho." $\mathrm{E}$, mais adiante: "A movimentação do Fundo, que, por seu turno, virá beneficiar as empresas, ampliando-lhes as possibilidades de investimento e até proporcionando-lhes maior volume de capital de giro, redundará em benefício para cada empregado, graças à correção monetária e aos juros dos depósitos nominais, anualmente percebidos, além da possibilidade de utilização total dos depósitos (...)" (Avulso do Congresso Nacional - Mensagem n. ${ }^{\circ}$ 13, de 1970 (CN), p. 2).

$\mathrm{E}$ assim se implantou a primeira fase do PIS, cujos verdadeiros resultados só poderiam ser avaliados com segurança após o decurso de tempo não muito curto, tendo em vista a complexidade de sua organização e o vultoso Fundo de Investimento que representava.

Natural estranhar que, menos de cinco anos passados desde o início da execução do Programa, tenha o respectivo Fundo de Participação, junto com o do PASEP, passado a integrar novo "pool" de recursos, denominado Fundo de Participação PIS-PASEP. Em empreendimentos vultosos, a mudança em tão breve tempo, poderia revelar falta daquela consistência aconselhada por CAIDEN e WILDAVSKY ${ }^{2}$ como uma das chaves de sucesso dos planejamentos em países pobres: "Do not run in all directions at once. Consistency may be conceived as horizontal (relative to several policies at a moment in time) or vertical (a single policy over a series of time periods extending 
into the future). Vertical consistency requires that the same policy be pursued over time, horizontal consistency that it mesh with others existing at the same time. The former requires continuity of a powerful regime able to enforce its preferences, the latter, tremendous knowledge of how policies interact."

Examinemos as alterações decorrentes da fusão.

\section{Programa de Integração Social - PIS (2. ${ }^{a}$ fase).}

A exposição de motivos interministerial que acompanhou projeto transformado na Lei Complementax 26/75 DCN 22-06-75, p. 1636) ressalta ter o II Plano Nacional de Desenvolvimento previsto a "universalização e o aperfeiçoamento dos mecanismos de remuneração indireta representados pelo PIS e PASEP".

Fez-se a fusão, não porque ela fosse necessária para assegurar a aplicação unitária dos recursos gerados pelos dois Programas, porque esse objetivo já fora atingido pela Lei Complementar 19, de 25-06-74, que confiou ao Banco Nacional de Desenvolvimento Econômico a elaboração dos programas necessários à aplicação dos recursos de ambos os Fundos de forma unificada e coordenada com os Planos Nacionais de Desenvolvimento. Tanto isto é verdade que a fusão se realizou com preservação das atuais fontes de receita, continuando os recursos do PIS canalizados através da Caixa Econômica Federal e os do PASEP por intermédio do Banco do Brasil.

Dois dos objetivos apontados na exposição de motivos interministerial realmente dependiam da fusão: $10^{\circ}$ ) Unificar a distribuição de recursos para permitir participação equitativa dos empregados e servidores públicos no patrimônio unificado. $\left.2 .^{\circ}\right)$ Acentuar o caráter retributivo dos critérios de participação em favor dos trabalhadores, das áreas pública e privada, de menor nível salarial.

A indiscriminação de recursos a distribuir, sem distinção entre a contribuição das empresas (lucro) e a dos órgãos públicos (parte da receita) tirou do PIS o caráter de forma indireta de participação dos trabalhadores nos lucros das empresas, transformando todo o mecanismo num misto de participação nos lucros por todos os assalariados (empregados e servidores públicos) e participação da renda nacional, talvez com o objetivo de aliviar o rigor da política salarial, que vem mantendo contidos os salários. 
Compreende-se que o Fundo de Participação do PASEP, criado contemporaneamente com o PIS (Lei Complementar $8 / 70$ ) se alimente de receitas públicas. Ao Estado cabe, em geral, desenvolver suas atividades sem fim lucrativo e, por isso, para a maioria dos servidores públicos, difícil seria falar em participação nos lucros. Aliás, a diversa denominação do Programa, mantida após a fusão, está a indicar não serem idênticos os dois mecanismos econômicos.

Podemos talvez justificar a fusão observando a evolução que se vem presenciando no desenvolvimento das atividades estatais e no sentido da alteração do regime jurídico aplicado aos servidores públicos porque:

$\left.1 .^{\circ}\right)$ Nota-se tendência sensível de aumento das atividades empresariais do Estado e mesmo certo "empresariamento" de atividades antes consideradas fora da exploração econômica, especialmente depois do Decreto-lei 200, de 25-02-67. A Reforma Administrativa admitiu, como órgão de administração indireta a autarquia, sem fim propriamente lucrativo, a empresa pública, de capital exclusivamente da União e que tem por finalidade a exploração da atividade econômica e a sociedade de economia mista, da qual participa, em minoria, o capital privado e cujo objetivo é também a exploração da atividade econômica. Paralelamente, vem aumentando aos poucos o número de servidores públicos ocupados em atividade lucrativa.

$\left.2 .^{\circ}\right)$ Embora tenha havido recuo na esfera constitucional quanto à aplicação da legislação trabalhista aos servidores públicos (Basta comparar a redação do art. 104 da Constituição de 1967, com o art. 106 da nova redação dada pela E.c. n. $\left.{ }^{\circ} 1 / 1969\right)$, o que se vem notando, em todos os níveis da Administração Pública, são manifestações do propósito de sujeitar os servidores públicos em geral ao regime da Consolidação das Leis do Trabalho. Admitir-se-ia, talvez, a manutenção de regime próprio para servidores que exerçam quase exclusivamente atribuições próprias do antigo Estado-gendarme.

Se a evolução se processar nesses dois sentidos, facilmente compreenderemos o Fundo Comum PIS-PASEP e a característica da participação nos lucros provavelmente, no futuro, delinear-se-á com mais nitidez.

Examinemos, finalmente, o propósito social de complementação salarial que inspirou a fusão PIS-PASEP e teve em vista o assalariado de mais baixos recursos econômicos. 
Tal como regulamentado, o Fundo Comum deverá ser distribuído de forma a garantir, caso haja recursos, as seguintes vantagens aos empregados e servidores cadastrados há, pelo menos, cinco anos e que percebam até cinco vezes o salário mínimo regional:

$\left.1 .^{a}\right)$ Depósito anual na conta de participação de, no mínimo, importância equivalente ao salário mínimo regional.

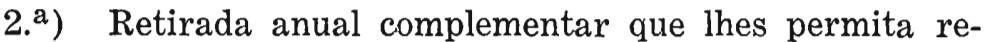
ceber importância igual ao salário mínimo regional, desde que o saldo das respectivas contas de participação comportem retirada desse valor. Este é o chamado $140^{\circ}$ salário.

Que porcentagem da população assalariada gozará de tais benefícios?

Valendo-nos de dados estatísticos referentes a 1970, chegamos à conclusão de que, do ponto de vista social, quanto à abrangência, a fusão PIS-PASEP atingirá as finalidades visadas pelo Governo.

De acordo com o Anuário Estatístico publicado pelo IBGE em 1972, havia, em 1970, 5.729.908 empregados. O maior salário mínimo em 1970 era de $\mathrm{Cr} \$ 187,20$, o que multiplicado por 5 dá Cr\$936,00. O mesmo Anuário apresenta a distribuição dos empregados pelas faixas de salário, estando Cr\$ 936,00 incluídos na faixa que abrange de $\operatorname{Cr} \$ 800,00$ a $\operatorname{Cr} \$ 999,00$. Encontramos 5.378.697 assalariados que percebiam até Cr\$ 999,00 , e isto representava $93 \%$ do total de empregados. Admitida hoje a mesma proporção, porque a alteração da política salarial não tem sido muito sensível, chega-se à conclusão de que praticamente a totalidade dos empregados, desde que cadastrados há, pelo menos, 5 anos, será beneficiada com a fusão.

Qual a proporção dos assalariados no total das pessoas que exercem atividade remunerada?

No "Mensário Estatístico" do INPS - n. ${ }^{\circ}$ especial de 1972, encontramos, em 1970, o total de 8.745 .422 contribuintes da previdência social, dos quais 7.071 .745 eram empregados e representavam mais de $80 \%$ das pessoas que trabalhavam. Vemos aqui, também, a confirmação de que considerável maioria da população brasileira trabalhadora será beneficiada.

Fixamo-nos no ano de 1970, porque tivemos em vista o estudo de FERnANDo A. REZENDE DA SILva ${ }^{9}$ que, baseado em estatística sobre imposto de renda referente a 1970 esclarece outro ângulo da questão: "Os dados de rendimento declarado, 
por cédula, em cada classe de renda, mostram que nas classes de renda mais baixa (menos de $\operatorname{Cr} \$ 1.650,00$ por mês) os rendimentos do trabalho assalariado respondem por mais de $70 \%$ da renda declarada, enquanto naqueles de renda mais elevada a mesma categoria de rendimentos representa menos de $30 \%$ do respectivo total." Temos, pois, prova da grande importância dos rendimentos do trabalho assalariado para a renda nacional e também mais uma confirmação de que considerável número de brasileiros será beneficiado com a fusão PIS-PASEP.

\section{Proscrição da Despedida Imotivada.}

Nấo poderíamos terminar sem salientar ainda uma vez a necessidade da proscrição da autorização legal de despedida imotivada, como primeira e principal medida de integração do trabalhador na vida da empresa e indispensável para que ele possa participar dos importantes mecanismos econômicos criados pelo Governo em benefício dos assalariados, para não falar da influência dessa medida na própria eficácia dos mesmos mecanismos econômicos. Apresentamos, em anexo, as conclusões aprovadas pelo Plenário.

\section{Referências Bibliográficas.}

1. Almansa Pastor, José Manuel. 1973. Derecho de la Seguridad Social. Editorial Tecnos. Madri, p. 153-154.

2. Caiden, Naomi e Wildavsky, Aaron. 1974. Planning and Budgeting in Poor Countries, John Wiley \& Sons, N.Y., p. 279.

3. Catharino, José Martins. 1972. Compêndio universitário de Direito do Trabalho. Ed. Jurídica e Universitária Ltda., p. 147.

4. Cesarino Júnior, Antonio Ferreira. 1962. A Participação nos lucros num programa de reformas de base, in Arquivos do Instituto de Direito Social, v. 14-2, p. 88.

5. Donato, Messias Pereira. 1975. Curso de Direito do Trabalho. Saraiva, p. 86.

6. Ferreira Filho, Manoel Gonçalves. 1975. Comentários à Constituição Brasileira, $3 .^{\circ}$ v., p. 188 , ed. Saraiva.

7. Magano, Octavio Bueno, a 1973. As novas tendências do Direito do Tra. balho. Tese de concurso. S. Paulo, p. 134. b 1975. Participação em lucros e Programa de Integração Social, in Revista do Tribunal Regional do Trabalho da $8 .^{a}$ Região, v. 8 n. ${ }^{\circ} 15$, p. 54.

8. Menezes, Geraldo Bezerra De. 1956. O Direito do Trabalho na Constituição Brasileira de 1946. Haddad, Ed. Rio, p. 140-141.

9. Silva, Fernando A. Rezende DA. 1974. O imposto sobre a renda e a justica fiscal. IPEA-INPES. Rio, p. 64.

10. SODRÉ, RUY DE AzEVEDo. 1962. A participação dos trabalhadores nos lucros das empresas. in Arquivos do Instituto de Direito Social. V. 14-2, p. 100. 
ANEXO.

\section{Congresso Latino Americano de Direito do Trabalho e Previdência Social - Tema I - Conclusões Aprovadas Pelo Plenário.}

Os congressistas, reunidos em torno do Tema I Participação em Lucros e Programa de Integração Social PIS, pela maioria dos convidados especiais e dos participantes que apresentaram trabalhos, reconheceram, no Programa de Integração Social, a regulamentação do art. $165, \mathrm{~V}$, da Constituição Federal, com a redação dada pela Emenda Constitucional n. ${ }^{\circ} 1 / 1969$, na parte referente ao direito do trabalhador de participação nos lucros de todas as empresas.

Trata-se de novo conceito de participação nos lucros, que dispensa a relação empregado-empresa em que trabalha, destinado a afastar o grande obstáculo, reconhecido pelos especialistas que tentaram elaborar o regulamento da participação direta nos lucros, determinada pela Constituição Federal de 1946, isto é, a diversa rentabilidade das empresas (algumas deficitárias) e a variada proporção entre o número de empregados de cada empresa e a respectiva rentabilidade.

Reconheceram também no PIS eficiente instrumento de redistribuição da renda nacional.

Divergências surgiram baseadas em posições doutrinárias tradicionais, que afirmam ser a participação nos lucros forma de integração do empregado na empresa para a qual trabalha e que constitui etapa que leva à co-gestão.

Ficou também claro ser o PIS forma de integração do empregado no desenvolvimento da empresa, não sendo suficiente para integrá-lo na vida da empresa, para o que poderá contribuir alteração de sua sistemática, pois trata-se de mecanismo flexível.

Reconhecendo a excelência dos mecanismos econômicos e sociais vigentes - PIS, FGTS e Sistema Nacional de Habitação, ressaltaram que todos eles têm como condição a existência de relação de emprego e, por isso, consideraram que a primeira medida necessária à integração do empregado na vida da empresa será a proscrição da atual autorização legal da despedida imotivada, com a exigência, para a despedida, de existência de motivo socialmente aceitável.

Os trabalhos e debates apresentaram valiosos elementos para determinação da natureza jurídica das contribuições empresariais e das quotas de participação, matéria que será mais pormenorizadamente analisada nos Anais do Congresso. 